\title{
ESTRATIGRAFÍA DEL NEÓGENO SUPERIOR AL SUR DE LA CUENCA TUMACO (PACÍFICO COLOMBIANO): LA FORMACIÓN CASCAJAL, PROPUESTA DE REDEFINICIÓN LITOESTRATIGRÁFICA
}

\author{
Sebastián Echeverrii ${ }^{1,2}$; Andrés Pardo-Trujillo ${ }^{1}$; $_{\text {Carlos Borrero }}$; \\ Agustín Cardona ${ }^{3}$; Sebastián Rosero ${ }^{1}$; Sergio A. Celis ${ }^{1}$; Sergio A. López ${ }^{4}$
}

DOI: http://dx.doi.org/10.18273/revbol.v38n4-2016003 (c) (1)

Forma de citar: Echeverri, S., Pardo-Trujillo, A., Borrero, C., Cardona, A., Rosero, S., Celis, S.A., y López, S.A. 2016. Estratigrafía del Neógeno Superior al sur de la cuenca Tumaco (Pacífico colombiano): la Formación Cascajal, propuesta de redefinición litoestratigráfica. Boletín de Geología, 38(4): 43-60.

\section{RESUMEN}

El conocimiento estratigráfico del relleno sedimentario del segmento onshore de la cuenca de ante-arco Tumaco es poco conocido y los trabajos existentes se fundamentan en el estudio de líneas sísmicas y pozos para la exploración de hidrocarburos, haciendo poco énfasis en las unidades más superficiales. Se presenta el estudio detallado de las rocas del Mioceno superior - Plioceno expuestas en el sector sur de la cuenca Tumaco. Los nuevos datos estratigráficos del pozo ANH-Tumaco 1-ST-S representan la sección más completa y mejor preservada de este intervalo de tiempo. Se integró esta información con nuevos datos de $\sim 200 \mathrm{~m}$ de secciones estratigráficas levantadas en afloramientos de los acantilados de la bahía de Tumaco y del río Patía. A partir de la descripción detallada de estas localidades, y siguiendo los parámetros de los códigos estratigráficos, se propone emplear el término Formación Cascajal para referirse a las rocas volcanoclásticas de edad Messiniense parte superior a Zancliense. Esta sucesión con un espesor observado de hasta $405 \mathrm{~m}$ está conformada principalmente por gruesos estratos lenticulares y ondulados de arenitas y conglomerados, con alto contenido de detritos volcánicos, en menor proporción, interestratificaciones de lodolitas y arenitas lodosas, localmente con icnofósiles y fósiles de bivalvos, gasterópodos, foraminíferos, equinodermos, crustáceos y restos de plantas bien conservadas, depositados en un ambiente de sedimentación deltaico influenciado por vulcanismo.

Palabras clave: Pacífico colombiano, ante - arco, cuenca Tumaco, código estratigráfico, vulcanismo.

\section{UPPER NEOGENE STRATIGRAPHY IN THE SOUTH OF TUMACO BASIN (COLOMBIAN PACIFIC): CASCAJAL FORMATION, LITHOSTRATIGRAPHIC REDEFINITION PROPOSAL}

\begin{abstract}
The stratigraphic knowledge of the sedimentary fill of the Tumaco onshore fore-arc basin is relatively poor. Previous works are based on the study of seismic lines and wells for hydrocarbon exploration with minor emphasis on the surface segments. We present a detailed study of the late Miocene - Pliocene rocks that outcrop in the southern Tumaco basin. New stratigraphic data from the ANH-Tumaco 1-ST-S well represent the most complete and best preserved sections for this time interval. This information is integrated with new data from descriptions of $\sim 200 \mathrm{~m}$ of stratigraphic sections visited in the coastal cliffs of the Tumaco bay and the Patia river. The detailed descriptions of these locations following parameters from stratigraphic codes allow us to propose the use of the term Cascajal Formation to refer to volcanoclastic rocks of Messinian - Zanclean age. This succession, with an estimated thickness of up to $405 \mathrm{~m}$, is composed mainly of thick lenticular and undulated layers of sandstones and conglomerates, with an important volcanic input. Minor interbedded mudstones and muddy sandstones are present too. Locally, ichnofossils, bivalves, gastropods, foraminifera, echinoderms, crustaceans and well-preserved plant remains were preserved, interpreted as formed in a deltaic system influenced by volcanism.

Keywords: Colombian Pacific, fore arc, Tumaco Basin, stratigraphic code, volcanism.

${ }^{1}$ Instituto de Investigaciones en Estratigrafía-IIES, Universidad de Caldas, Calle 65 No. 26-10. Manizales, Colombia. Teléfono: +57-(6)-8780015 ext. 13433, juansebasecheverri@gmail.com, sebastian.echeverri@usp.br

2 Instituto de Geociências-IGC; Universidade de São Paulo, Rua do Lago, 562, São Paulo, Brasil.

${ }^{3}$ Escuela de Procesos y Energía, Universidad Nacional de Colombia, Facultad de Minas, Carrera 80 No 65 - 223. Medellín, Colombia.

${ }^{4}$ Agencia Nacional de Hidrocarburos-ANH, Avenida Calle 26 No. 59 - 65 Piso 2. Bogotá, Colombia.
\end{abstract}




\section{INTRODUCCIÓN}

El conocimiento de la geología de superficie de la región Pacífica colombiana es insuficiente ya que por ser una región principalmente plana y selvática posee escasos afloramientos y dificultades de acceso. Esto unido a problemas sociales han hecho que los mapas geológicos tengan escaso control de campo y las columnas estratigráficas disponibles sean muy generalizadas, de forma que los trabajos existentes se basan en cartografía geomorfológicageológica a escala 1:100.000 (e.g. Nivia et al., 2003), y en la interpretación de líneas sísmicas y pozos exploratorios antiguos (Remolinogrande-1, Majagua-1, Chagüí-1). En consecuencia, la estratigrafía de la cuenca de ante arco Tumaco es poco conocida y hasta el momento no son claras las relaciones espacio-temporales entre las unidades, lo que hace difícil establecer una sólida nomenclatura estratigráfica para las unidades de roca.
Solo a partir de los estudios de exploración petrolera (e.g. Suárez-Rodríguez, 1990) se comienza a establecer una nomenclatura estratigráfica unificada, aunque persiste la ausencia de datos de campo y los reportes cartográficos existentes (Nivia et al., 2003) hacen poco énfasis en los problemas estratigráficos de esta área. En el 2008 la Agencia Nacional de Hidrocarburos-ANH inició una campaña de perforación de pozos estratigráficos en el Pacífico colombiano (e.g. pozos ANH-Tumaco 1-ST$\mathrm{S}$ y ANH-Tumaco 1-ST-P), los cuales aportan nueva información, especialmente de las rocas neógenas. En este trabajo, a partir de la integración de la información bibliográfica, con los análisis lito- y bioestratigráficos detallados del pozo corazonado ANH-Tumaco 1-ST-S localizado en el sector de Tangareal a un costado de la vía Tumaco - Pasto (FIGURA 1), y la nueva información obtenida en los afloramientos del río Patía y en los acantilados costeros de la bahía de Tumaco (FIGURA 1), se presenta un análisis litoestratigráfico para las rocas de edad Mioceno superior - Plioceno expuestas en el sur de la cuenca Tumaco y se redefine la Formación Cascajal.

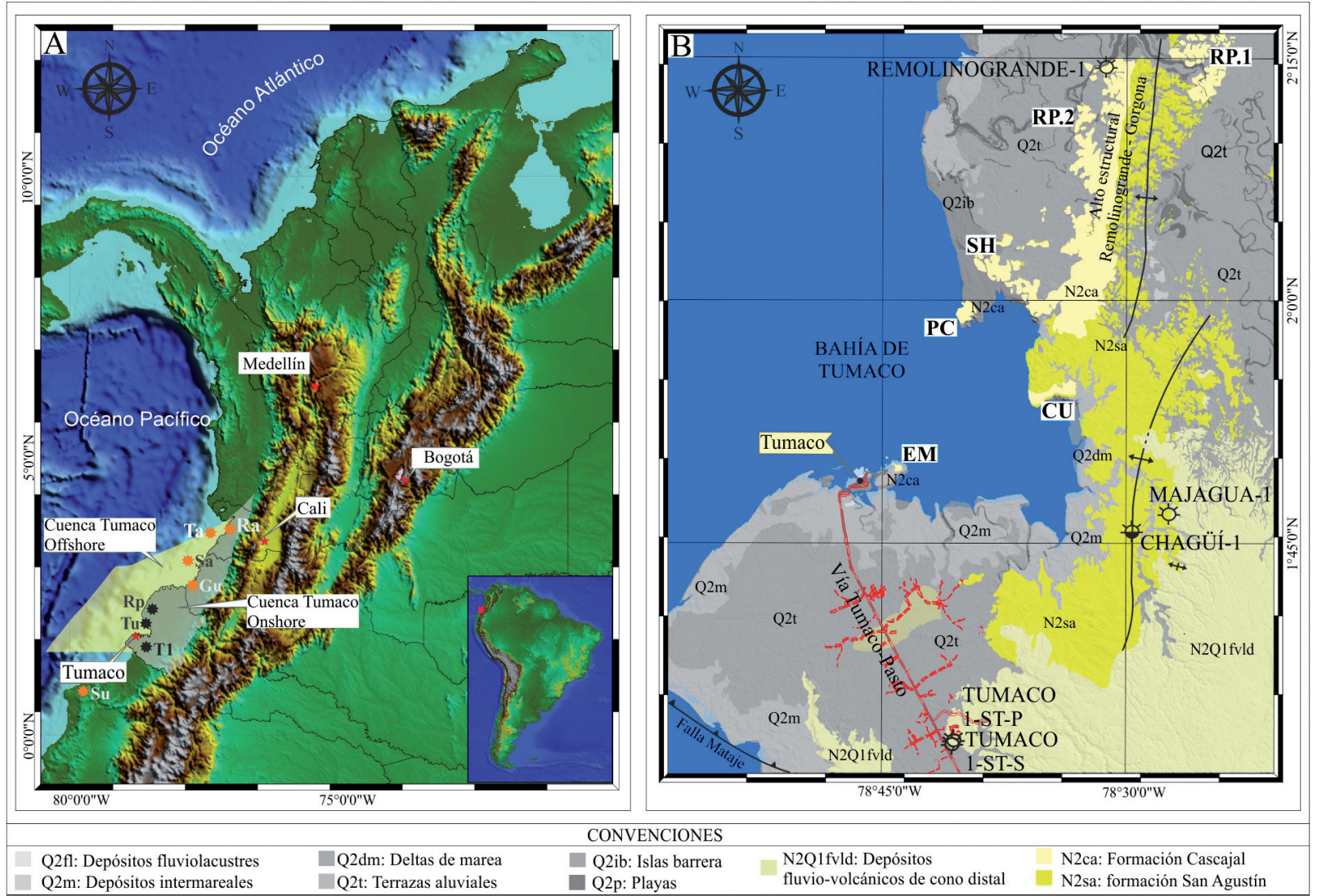

FIGURA 1. A. Mapa de localización de la cuenca Tumaco con los segmentos offshore y onshore. Las estrellas negras representan las áreas reportadas en este estudio: T1: Pozo ANH-Tumaco 1-ST-S, Tu: Bahía de Tumaco, Rp: Río Patía; mientras que las naranja corresponden a secciones de la literatura. Su: Mbr. Súa; Gu: Fm. Guapi; Ra: Fm. Raposo; Sa: Pozo Sandi-1; Ta: Pozo Tambora-1. B. Mapa geológico de la bahía de Tumaco con la localización de los pozos exploratorios perforados en el segmento onshore y los afloramientos estudiados en los acantilados costeros y en el sistema deltaico del río Patía (modificado de ANH - Universidad de Caldas, 2011a; Patiño et al., 2011): RP1 y RP2: Río Patía; SH: Salahonda; PC: Punta Cascajal; CU: Curay; EM: El Morro. 


\section{METODOLOGÍA}

Se realizó una revisión y evaluación de la información disponible, integrada con los nuevos datos sedimentológicos, cartográficos y paleontológicos obtenidos en los corazones del pozo ANH-Tumaco 1-ST-S, los ripios del pozo Remolinogrande-1 y a partir del estudio estratigráfico de cinco secciones de afloramientos en los sectores de la bahía de Tumaco y el río Patía (FIGURA 1). Adicionalmente, la información sísmica, geocronológica y termocronológica obtenida en trabajos anteriores fue útil como criterio de correlación tectono-estratigráfica (e.g. Suárez-Rodríguez, 1990; López, 2009). La nomenclatura propuesta se basa en la evaluación de toda la información colectada y sigue los parámetros de la Guía Estratigráfica Internacional (ISSC, 1994), el Código Norteamericano de Estratigrafía (NASC, 2005) y la carta cronoestratigráfica internacional (Cohen et al., 2013).

\section{ANTECEDENTES ESTRATIGRÁFICOS}

La estratigrafía de la cuenca Tumaco es poco conocida y presenta diferentes nomenclaturas estratigráficas. La utilizada en estudios regionales (Arango y Ponce, 1980; González, 2008), sigue la propuesta por Van der Hammen (1958), quien realizó una síntesis de la estratigrafía del "Terciario" para el valle interandino del Pacífico (FIGURA 2). Entre las unidades de edad Plioceno reportadas por el autor, se encuentra la formación Guapi, que suprayace discordantemente a la formación Naya (Oppenheim, 1949) de edad Mioceno (FIGURA 2).
De acuerdo con la interpretación sísmica y la información de los pozos perforados en los segmentos offshore y onshore de la cuenca Tumaco, SuárezRodríguez (1990) establece una propuesta estratigráfica que ha servido de referencia para estudios posteriores (Escovar et al., 1992; Galindo y Torres, 1995; Earth Satellite Corporation, 1999; Suárez-Rodríguez, 2007; Becerra y Usma, 2008; Correa et al., 2008; Echeverri et al., 2011; ANH-Universidad de Caldas, 2011a y b; FIGURA 2). Suárez-Rodríguez (1990) propone emplear el término formación Guapi para la unidad constituida por conglomerados basales delgados alternados con facies lodosas-arenosas presentes en el tope de los pozos Tambora-1 y Sandi-1, e interpreta un ambiente de plataforma de edad Plioceno(?) para esta sucesión. Por otro lado, hacia la parte norte de la cuenca Tumaco, Aspden (1984) y Aspden y Nivia (1984) proponen dividir la sucesión sedimentaria que aflora en la llanura costera del departamento del Valle del Cauca en dos unidades de edad no más antigua que Neógeno (FIGURA 2): 1) formación Mayorquín compuesta principalmente por lodolitas, y 2) formación Raposo dominada por conglomerados y arenitas. Las relaciones estratigráficas y la distribución cronoestratigráfica de estas unidades no es clara debido a la escasa resolución bioestratigráfica y ausencia de afloramientos continuos, lo cual ha generado correlaciones confusas de estas unidades descritas originalmente en el Pacífico del sur de Buenaventura, extendiendo esta nomenclatura hasta el norte del delta del río San Juan (Montoya, 2002; Salazar, 2002; Patiño et al., 2008; Correa et al., 2008) y hasta el suroeste del departamento de Nariño (Nivia et al., 2003; INGEOMINAS-IGAC, 2005; López, 2009).

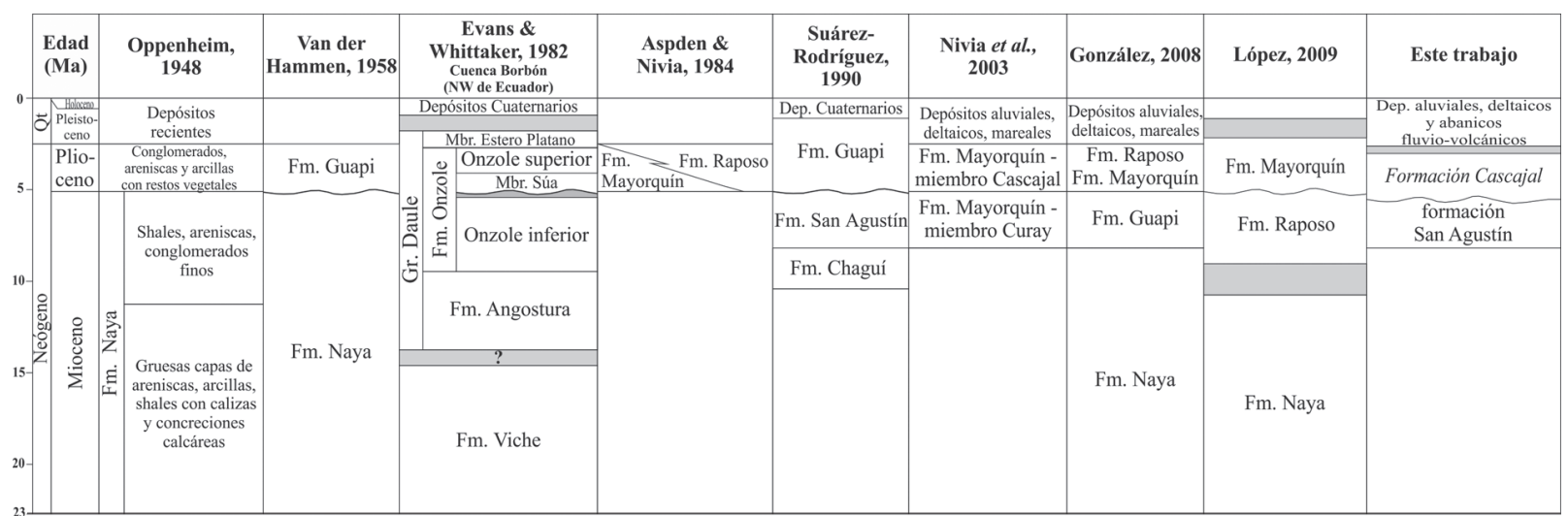

FIGURA 2. Carta de correlación estratigráfica para la cuenca de ante-arco Tumaco onshore.

Adicionalmente en la bahía de Tumaco, la formación Mayorquín es subdividida por Nivia et al. (2003) en dos miembros: uno arenoso, el miembro Curay; y otro calcáreo, el miembro Cascajal (FIGURA 2).
Estos autores, se basan en la similitud de los rasgos geomorfológicos y fisiográficos de la unidad con las rocas expuestas en el segmento costero del Valle del Cauca. Además, la subdivisión de esta unidad en los 
miembros Cascajal y Curay, está fundamentada en las variaciones litológicas por cambios laterales de facies. Nivia et al. (2003) describen el miembro Cascajal en el sector de punta Cascajal, isla del Gallo y en los alrededores de Salahonda, como un intervalo marino - transicional (deltaico) constituido por margas y biomicritas empaquetadas. En este sector son comunes los estratos gruesos de arenitas de grano fino, arcillosas, relativamente blandas, interestratificadas con capas delgadas de arenitas de grano fino (Nivia et al., 2003). Por otro lado, hacia el extremo SW de la cuenca Tumaco onshore, a partir del estudio de pozos exploratorios (Remolinogrande-1 y ANHTumaco 1-ST-S) y afloramientos de la bahía de Tumaco, Echeverri et al. (2011) sugieren redefinir el miembro cascajal propuesto por Nivia et al. (2003) y emplear el término formación Cascajal. Esta unidad, constituida principalmente por areniscas, areniscas conglomeráticas y conglomerados polimícticos fue depositada en un ambiente de sedimentación deltaico dominantemente siliciclástico, que contrasta con la definición calcárea original para el miembro Cascajal en la misma área (Nivia et al., 2003).

\section{RESULTADOS}

Revisión y redefinición de la Formación Cascajal (intervalo Mioceno superior - Plioceno); Proponentes y procedencia del nombre: Nivia et al. (2003) emplean por primera vez el término miembro Cascajal en el estudio de Geomorfología y Geología de la Plancha 383 Tumaco. El nombre proviene de la saliente "Punta Cascajal", localizada hacia el sur del municipio de Francisco Pizarro ("población de Salahonda", FIGURA 1 y TABLA 1), al $\mathrm{N}$ de la bahía de Tumaco. En este trabajo, a partir de una descripción estratigráfica detallada del segmento SW de la cuenca Tumaco onshore, se eleva formalmente el rango a formación.

TABLA 1. Localización y datos estratigráficos del pozo ANH-Tumaco 1-ST-S y afloramientos.

\begin{tabular}{|c|c|c|c|c|c|}
\hline Pozo/Sección & $\begin{array}{l}\text { Pozo/columna } \\
\text { estratioráfica (m) }\end{array}$ & $\begin{array}{c}\text { Intervalos } \\
\text { estratigráficos (m }\end{array}$ & $\begin{array}{c}\text { Unidades } \\
\text { estratioráficas }\end{array}$ & \multicolumn{2}{|c|}{ Coordenadas } \\
\hline \multirow{3}{*}{$\begin{array}{c}\text { ANH-TUMACO } \\
\text {-1ST-S }\end{array}$} & \multirow{3}{*}{579} & $540-579$ & $\begin{array}{c}\text { Llanura deltaica de } \\
\text { Río Mira }\end{array}$ & \multirow{3}{*}{$1^{\circ} 30^{\prime} 56.20 ” \mathrm{~N}$} & \multirow{3}{*}{$78^{\circ} 41^{\prime} 48.66^{\prime \prime} \mathrm{W}$} \\
\hline & & $135-540$ & Fm. Cascajal & & \\
\hline & & $0-135$ & Fm. San Agustín & & \\
\hline EL MORRO (EM) & 21 & 21 & Fm. Cascajal & $1^{\circ} 48^{\prime} 49.64 " ' \mathrm{~N}$ & $78^{\circ} 44^{\prime} 98.94$ ' W \\
\hline SALAHONDA (SH) & 55.5 & 55.5 & Fm. Cascajal & $2^{\circ} 2 ' 16.84{ }^{\prime \prime} \mathrm{N}$ & $78^{\circ} 39^{\prime} 18.56^{\prime \prime} \mathrm{W}$ \\
\hline $\begin{array}{c}\text { PUNTA CASCAJAL } \\
(\mathrm{PC})\end{array}$ & 39.5 & 39.5 & Fm. Cascajal & $1^{\circ} 59^{\prime} 16.76 ” \mathrm{~N}$ & $78^{\circ} 40^{\prime} 13.04^{\prime \prime} \mathrm{W}$ \\
\hline CURAY (CU) & 40 & $15.4-40$ & $\begin{array}{c}\text { Fm. Cascajal } \\
\text { Fm. San Agustín }\end{array}$ & $1^{\circ} 54^{\prime} 4.14^{\prime \prime} \mathrm{N}$ & $78^{\circ} 21^{\prime} 16.79^{\prime \prime} \mathrm{W}$ \\
\hline RÍO PATÍA 1 (RP1) & 21.8 & 21.8 & Fm. Cascajal & $2^{\circ} 18^{\prime} 51.96 ” \mathrm{~N}$ & $78^{\circ} 21^{\prime} 16.79^{\prime \prime} \mathrm{W}$ \\
\hline RÍO PATÍA 2 (RP2) & 28.4 & 28.4 & Fm. Cascajal & $2^{\circ} 12^{\prime} 0.26^{\prime \prime} \mathrm{N}$ & $78^{\circ} 32^{\prime} 44.22^{\prime \prime} \mathrm{W}$ \\
\hline
\end{tabular}

Localidad tipo: Pozo ANH-Tumaco 1-ST-S y los acantilados expuestos en el extremo NW de la bahía de Tumaco, a lo largo de la saliente "Punta Cascajal", al sur del municipio de Francisco Pizarro (FIGURA 1).

Posición estratigráfica y edad: la Formación Cascajal suprayace en contacto paraconforme erosivo a las lodolitas de plataforma - prodelta de la formación San Agustín, y a su vez es suprayacida discordantemente por los "Depósitos Fluvio-Volcánicos de Cono Distal" (sensu ANH-Universidad de Caldas, 2011a), el "Glacis del Diviso" (sensu Nivia et al., 2003; González, 2008) o por los depósitos de la llanura deltaica de los ríos Mira y Patía. 
Análisis quimio-estratigráficos de ${ }^{87} \mathrm{Sr} /{ }^{86} \mathrm{Sr}$ en conchas de moluscos del pozo ANH-Tumaco 1-ST-S (Rosero et al., 2012) indican una edad Plioceno inferior (Zancliense). Dataciones $\mathrm{U} / \mathrm{Pb}$ en circones detríticos realizados en la sección de la isla del Morro y en el pozo ANH-Tumaco 1-ST-S (Echeverri et al., 2015) indican una edad igual o más joven que 4,8 y 4,1 Ma (Zancliense). Análisis de foraminíferos de una muestra de la Formación Cascajal en el "Quesito" (isla del Morro), asignan una edad Zancliense tardío (ANH - Universidad de Caldas, 2011a). Datos micropaleontológicos obtenidos en el pozo ANH-Tumaco 1-ST-S (ANH - Universidad de Caldas, 2011b), indican que la edad de esta unidad es Mioceno superior - Plioceno inferior (Messiniense parte superior a Zancliense). A partir de la integración de edades micropaleontológicas, geocronológicas y quimioestratigráficas obtenidas en la Formación Cascajal, en este trabajo se asigna una edad Messiniense parte superior a Zancliense.

\section{Descripción Geológica:}

Concepto: constituida por una sucesión de arenitas, arenitas conglomeráticas y conglomerados, en ocasiones fosilíferas, con alternancia de lodolitas y limolitas fosilíferas. Se establece formalmente la Formación Cascajal como la sucesión volcanoclástica de arenitas con intercalaciones conglomeráticas que suprayace a la formación San Agustín. Se diferencia de la unidad infrayacente por la desaparición de niveles dominantemente lutíticos del tope de la formación San Agustín y la aparición de los primeros niveles gruesos de arenitas y conglomerados, con bases erosivas y abundantes fragmentos volcánicos, los cuales constituyen la base de esta unidad.

Distribución geográfica: esta unidad fue reconocida en la llanura costera del Pacífico nariñense, en los sectores de Punta Cascajal, Salahonda, Curay, isla de El Morro, área del actual brazo principal del río Patía, en afloramientos al sur de la población de Tumaco y en los pozos ANH-Tumaco 1-ST-S y 1-STP (FIGURA 1).

Espesor: a partir de la información obtenida en los núcleos de perforación del pozo ANH-Tumaco 1-ST-S, la Formación Cascajal presenta un espesor aparente de $405 \mathrm{~m}$ (TABLA 1), el cual se aproxima al real por los buzamientos de bajo grado observados en campo $\left(\sim 6^{\circ}\right)$. En los acantilados costeros localizados en la bahía de Tumaco se levantaron cuatro secciones estratigráficas (FIGURA 1; TABLA 1), denominadas Punta Cascajal (39,5 m), Salahonda (55,5 m), El Morro (21 m) y Curay
(24,6 m); mientras que en el área deltaica del río Patía se reportan cinco secciones estratigráficas aisladas, con un espesor conjunto de $\sim 50 \mathrm{~m}$ (Patiño et al., 2011).

Límite inferior: de acuerdo con la información de registros de resistividad, SP y Gamma Ray del pozo gemelo ANH-Tumaco 1-ST-P, localizado en la misma posición que el pozo ANH-Tumaco 1-ST-S (FIGURA 1), junto con los afloramientos y corazones del pozo ANH-Tumaco 1-ST-S, esta unidad está limitada hacia la base por una disconformidad, definida como una superficie erosiva que pone en contacto a dos unidades o secuencias sedimentarias paralelas entre sí. Esta superficie, también denominada como disconformidad planar o límite paraconforme erosivo, pone en contacto a las arenitas y conglomerados de la Formación Cascajal con la formación San Agustín (FIGURAS 2, 3 y 4). Se presenta un cambio litológico marcado por la aparición de arenitas y conglomerados con contactos basales erosivos de la Formación Cascajal y la desaparición de dominios de lodolitas fosilíferas bioturbadas y turbiditas de la formación San Agustín. Del mismo modo, contrastes de facies sísmicas y de impedancia acústica identificados a partir de trabajos de interpretación sísmica definen un contacto discordante entre estas unidades (e.g. Suárez-Rodríguez, 1990; Cediel et al., 2010; Martínez y López, 2010). Si bien el límite entre las formaciones San Agustín y Cascajal es paraconforme erosivo, la integración de los datos micropaleontológicos presentados en este trabajo con los de la literatura (Bedoya et al., 2013), muestran una sucesión de biozonas continua con ausencia de hiatos bioestratigráficos.

Límite superior: en el pozo ANH-Tumaco 1-ST-S, está definido por una discordancia angular que pone en contacto a capas muy gruesas de sublitoarenitas lodosas de grano muy fino y limolitas con fósiles de moluscos y foraminíferos del tope de la Formación Cascajal, con depósitos cuaternarios muy gruesos, pobremente consolidados, de litoarenitas y sublitoarenitas de grano grueso de la llanura deltaica del río Mira (FIGURAS 3 y 4). En los acantilados de la bahía de Tumaco (secciones de Cascajal, Salahonda, El Morro), el límite superior está definido por la superficie de erosión actual, o por una discordancia angular que pone en contacto a una serie de capas gruesas y muy gruesas de litoarenitas de la Formación Cascajal con depósitos deltaicos de los ríos Mira y Patía, con "Depósitos Fluvio-volcánicos de cono distal" o con el "Glacis del Diviso" (González, 2008; ANH-Universidad de Caldas, 2011a). 


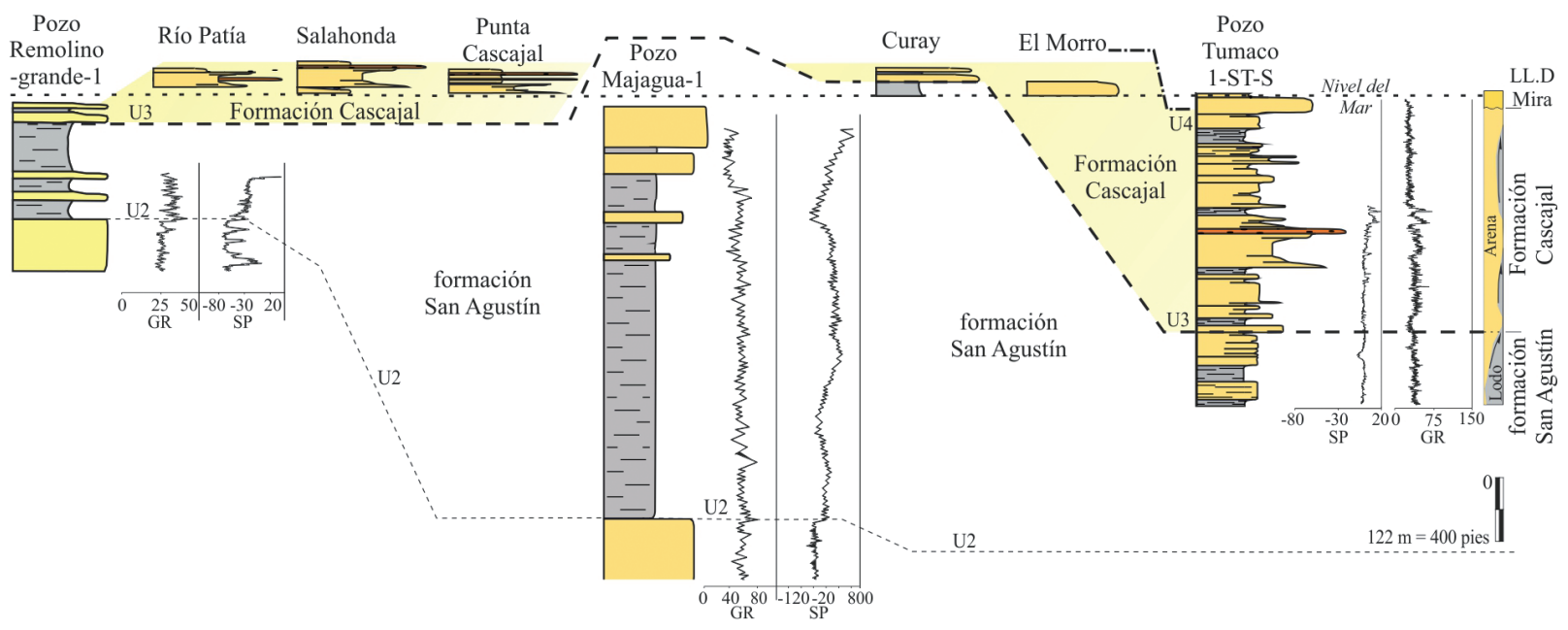

FIGURA 3. Correlación estratigráfica generalizada de los afloramientos estudiados en la bahía de Tumaco y los pozos exploratorios perforados en la cuenca Tumaco onshore. Se presentan registros de rayos gamma (GR) y potencial espontáneo (SP) para los pozos, y en las líneas punteadas U2, U3 y U4, los límites de secuencia definidos a partir de discontinuidades estratigráficas (López, 2009). En el extremo derecho se presenta la relación gráfica entre arenitas + conglomerados vs lodolitas de las formaciones San Agustín, Cascajal y llanura deltaica del río Mira (LL.D Mira) en el pozo ANH-Tumaco 1-ST-S.

Estratotipos: para la Formación Cascajal se define un estratotipo compuesto, el cual está definido por un holoestratotipo y cinco paraestratotipos que constituyen estratotipos suplementarios empleados en la definición formal de una unidad litoestratigráfica, siguiendo la propuesta citada en el numeral 4B4 de la Guía Estratigráfica Internacional (ISSC, 1994).

Holoestratotipo: el pozo ANH-Tumaco 1-ST-S posee la sección más completa de la Formación Cascajal y por tanto se propone como holoestratotipo. Localizado a un costado de la vía Tumaco - Pasto, en el sector de Tangareal en la rivera del Río Mira, a $\sim 30 \mathrm{~km}$ al SE del municipio de Tumaco - Nariño. En este pozo de $579 \mathrm{~m}$ de profundidad total se reconocen $405 \mathrm{~m}$ de la Formación Cascajal (TABLA 1).

Paraestratotipos: se definen cinco paraestratotipos que constituyen secciones suplementarias empleadas en la definición litoestratigráfica formal de la Formación Cascajal (FIGURA 1), los cuales representan la heterogeneidad y algunos rasgos particulares, que no se encuentran o no son expuestos en el Holoestratotipo: 1) Acantilados expuestos en el sector de Punta Cascajal (Sector $\mathrm{N}$ de la bahía de Tumaco, a $\sim 7 \mathrm{~km}$ al $\mathrm{S}$ del municipio de Francisco Pizarro). 2) Acantilados expuestos en la población de Salahonda (Sector N de la bahía de Tumaco, al $\mathrm{S}$ del delta de río Patía; en el estero localizado a $\sim 500 \mathrm{~m}$ al $\mathrm{N}$ del municipio de Francisco Pizarro). 3) Acantilados expuestos al NE de la Isla del Morro, en el municipio de Tumaco (Sector SW de la bahía de Tumaco, al N del río Mira). 4) Parte superior de los acantilados expuestos en el sector de Curay, hacia el $\mathrm{N}$ de la bocana del mismo nombre (sector E de la bahía de Tumaco, a $\sim 20 \mathrm{~km}$ al NE del municipio de Tumaco). 5) Afloramientos aislados en el área deltaica del río Patía (Sector N de la bahía de Tumaco, entre $\sim 20$ y 50 $\mathrm{km}$ al NE del municipio de Francisco Pizarro).

Litología: dado que la sección más completa y mejor preservada de la Formación Cascajal la constituye el pozo ANH-Tumaco 1-ST-S (FIGURA 3), se pueden reconocer tres intervalos con características diferentes que, de base a techo, son: 1) Intervalo 135-257 m: Intercalaciones de arenitas (predominantes) y lodolitas, y ocasionalmente conglomerados de guijos y guijarros. A la base se presenta una sucesión de arenitas con intercalaciones de lodolitas y limolitas, en proporciones variables, y hacia el techo es notable el aumento de las lodolitas. Los contactos entre las capas son netos y con menor frecuencia erosivos. En general las arenitas son de grano medio y fino, en capas desde delgadas 
hasta muy gruesas (desde 0.09 hasta $12 \mathrm{~m}$ ); localmente pueden presentar glauconita, pellets glauconitizados, estructuras de escape de agua y fallas sin-sedimentarias. Es común observar intraclastos lodosos en arenitas masivas de grano medio - grueso, bioturbación en arenitas masivas de grano fino, y con menor frecuencia arenitas de grano medio - grueso laminadas. Localmente pueden presentar cintas conglomeráticas de pumitas, capas medias de conglomerados de guijos y gránulos de origen volcánico, con abundantes fragmentos de pómez (FIGURAS 4A y B), que gradan normalmente a arenitas volcánicas gruesas y medias. Las lodolitas se encuentran bioturbadas, en estratos principalmente delgados y medios (desde 0,05 hasta $0,3 \mathrm{~m})$, pero ocasionalmente alcanzan espesores gruesos (hasta de 2,1m). Es común la presencia de facies heterolíticas, con estratificación flaser, wavy, lenticular y bioturbación sobreimpuesta (FIGURAS 4F y G). Las capas de limolitas, arenitas muy finas y finas, pueden presentar fósiles de bivalvos, gasterópodos, equinodermos, peces y restos de madera carbonizada con tamaños mayores a $2 \mathrm{~cm}$. 2) Intervalo 257-350 $\mathrm{m}$ : Alternancia de estratos medios hasta muy gruesos (desde 0,25 hasta $10 \mathrm{~m}$ ) de arenitas y conglomerados con bases erosivas, rellenando canales, con esporádicas intercalaciones de estratos delgados a medios (desde 0,1 hasta $0,3 \mathrm{~m}$ ) de lodolitas y limolitas. Las arenitas presentan tamaños de grano desde muy fino hasta grueso, mala selección, un marcado aporte volcánico y contienen fósiles de moluscos mal preservados, equinodermos y foraminíferos. Los conglomerados, que están dispersos a lo largo de la sucesión, presentan fábrica maciza clasto-soportada y están compuestos por gránulos, guijos y guijarros subredondeados, de rocas volcánicas, pumitas, arenitas, lodolitas y chert. Las lodolitas y arenitas muy finas pueden contener restos de plantas bien preservados y láminas lodosas ricas en materia orgánica (FIGURA 4C). 3) Intervalo 350$540 \mathrm{~m}$ : Alternancia de lodolitas, limolitas y arenitas de grano muy fino a medio, en menor proporción arenitas gruesas rellenando canales, en capas delgadas hasta muy gruesas con bases erosivas (desde 0,07 hasta $10 \mathrm{~m}$ ), con laminación plana paralela, ondulada y lenticular. Los intervalos de arenitas internamente pueden ser macizas o laminadas (plana paralela, wavy), lodosas, bioturbadas (FIGURAS 4D, H e I), con abundantes fósiles de moluscos (FIGURA 4E). Es común observar bivalvos, gasterópodos, equinodermos, escafópodos, crustáceos, peces, foraminíferos y restos de plantas, mientras que los corales(?), pellets glauconitizados y glauconita son menos comunes.

La caracterización litológica del pozo ANHTumaco 1-ST-S, se complementó con el estudio de secciones estratigráficas en afloramientos de hasta $\sim 55 \mathrm{~m}$ de espesor presentes en la bahía de Tumaco (FIGURAS 5, 6 y 7). Los afloramientos localizados en las secciones de Salahonda, Punta Cascajal, Isla del Morro y Río Patía, se correlacionan con la parte media y superior de la Formación Cascajal, mientras que la localidad de Curay corresponde a la base. En general, están constituidos por una sucesión volcanoclástica de estratos ondulados y lenticulares de arenitas, arenitas conglomeráticas, y conglomerados alternados con lodolitas y limolitas. Los estratos son medios, gruesos y muy gruesos (desde 0,2 hasta $14 \mathrm{~m}$, FIGURAS 5, 6 y 7). Las arenitas son de grano fino a grueso, macizas, o con laminación plana paralela, ondulada e inclinada a pequeña y gran escala, y contienen intraclastos de arcilla y ocasionalmente cintas conglomeráticas (FIGURAS 5, 6 y 7 ). Composicionalmente corresponden a litoarenitas feldespáticas, y arenitas arcósicas, conformadas por granos de cuarzo, feldespato, anfíbol, biotita y en menor proporción moscovita. Los fragmentos líticos son principalmente de rocas volcánicas porfiríticas y pumitas de composición andesítica-dacítica.

En los sectores de Salahonda y Punta Cascajal es frecuente observar sucesiones granocrecientes de litoarenitas y litoarenitas feldespáticas, conglomeráticas, y conglomerados de gránulos y guijos, en capas amalgamadas de espesores decimétricos y métricos, con geometrías onduladas, lenticulares y canaliformes (desde 0,3 hasta 6 m; FIGURAS 5A, B y H). Hacia la base se observan estratos de arenitas finas con brechas y pliegues recumbentes asociados a estructuras de deformación sin-sedimentaria (FIGURAS 5C y D); así como superficies erosivas con abundantes intraclastos de arcilla desde tamaños milimétricos hasta decimétricos (FIGURAS 5E y F), gradación normal, y laminaciones plana paralela, ondulosa, difusa e inclinada tangencial y planar (FIGURAS 5F y G). Además, se observan esporádicas intercalaciones de capas delgadas de lodolitas macizas de color gris parduzco, poco densas, que podrían corresponder a niveles tobáceos retrabajados. 


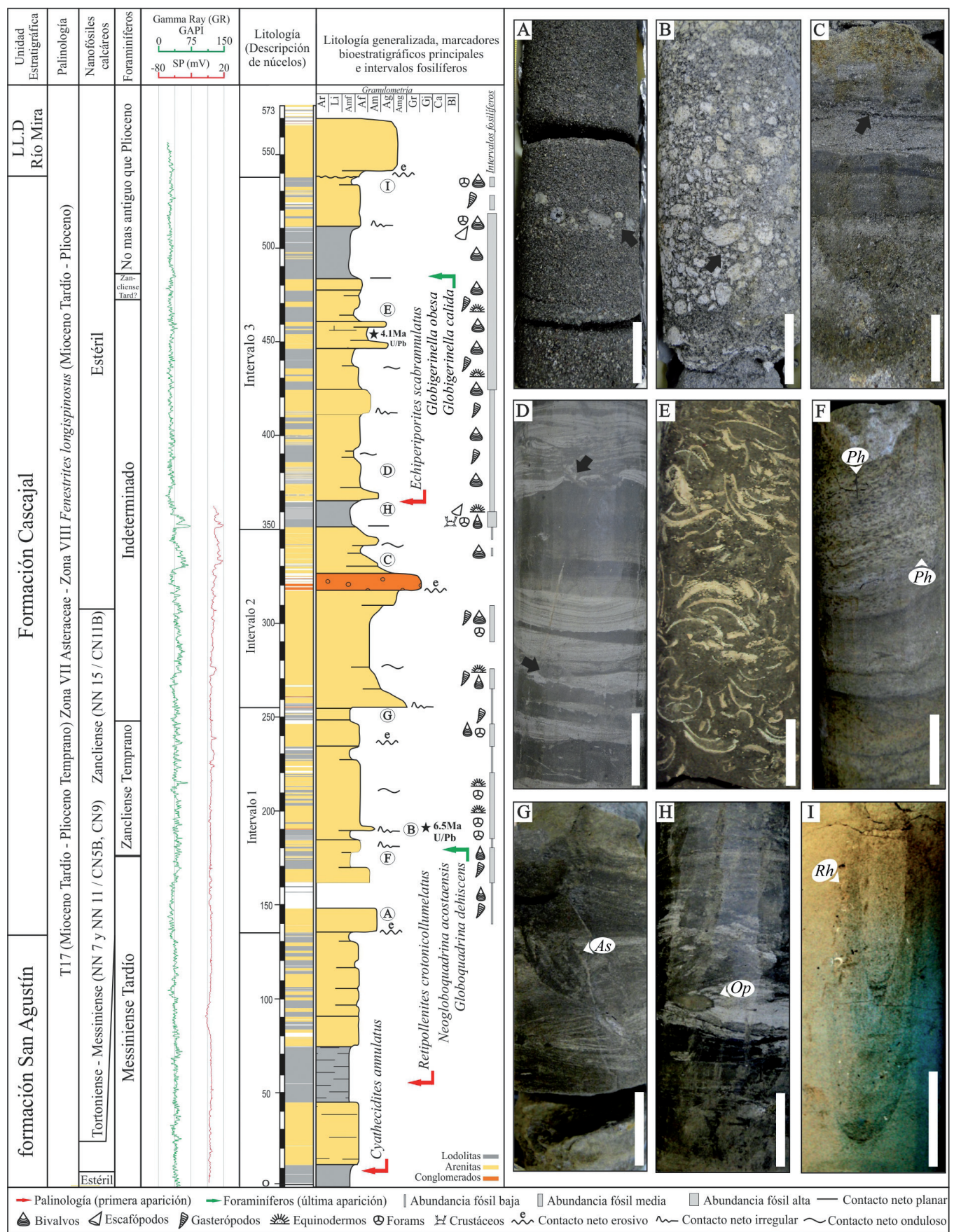

FIGURA 4. Sección estratigráfica de la Formación Cascajal y tope de la formación San Agustín en el pozo ANH-Tumaco 1-ST-S. Se presentan las edades micropaleontológicas reportadas en este estudio y los registros de rayos gamma (Gr) y potencial espontáneo (SP) (Schlumberger, 2011; T.G.T. Gamas, 2011). En el centro se presenta el perfil litológico con límites de capas, edades detríticas $\mathrm{U} / \mathrm{Pb}$ de máxima depositación (Echeverri et al., 2015), marcadores bioestratigráficos principales e intervalos fosilíferos. A la derecha se presentan fotografías de algunas litologías e icnofósiles: A. Arenita de grano medio, maciza, resaltando la concentración de granos de pumitas en cintas paralelas a la estratificación. Metro 136,5. B. Conglomerado volcánico matriz-soportado, gradado, compuesto por pumitas y cristales. Metro 189,94. C. Arenita media a fina con láminas limosas. Se resalta una lámina de materia orgánica carbonizada. Metro 331,43. D. Facies heterolíticas de lodolitas y arenitas muy finas, bioturbadas, con laminación ondulosa y wavy. Las flechas negras resaltan galerías subhorizontales. Metro 379,21. E. Arenitas lodosas muy finas, macizas, fosilíferas y bioturbadas con abundantes moluscos. Metro 467,6. F. Traza monoespecífica del icnogénero Phycosiphon $(P h)$ en limolitas arenosas laminadas. Metro 172,65. G. Icnogénero Asterosoma $(A s)$ en facies heterolíticas, laminadas, de limolitas y arenitas muy finas. Metro 251,6 . H. Icnogénero Ophiomorpha (Op) en facies heterolíticas con laminación lenticular. Metro 359,55. I. Icnogénero Rhizocorallium (Rh) en sublitoarenitas lodosas muy finas. Metro 536,85. La escala para las fotografías corresponde a $3 \mathrm{~cm}$. 


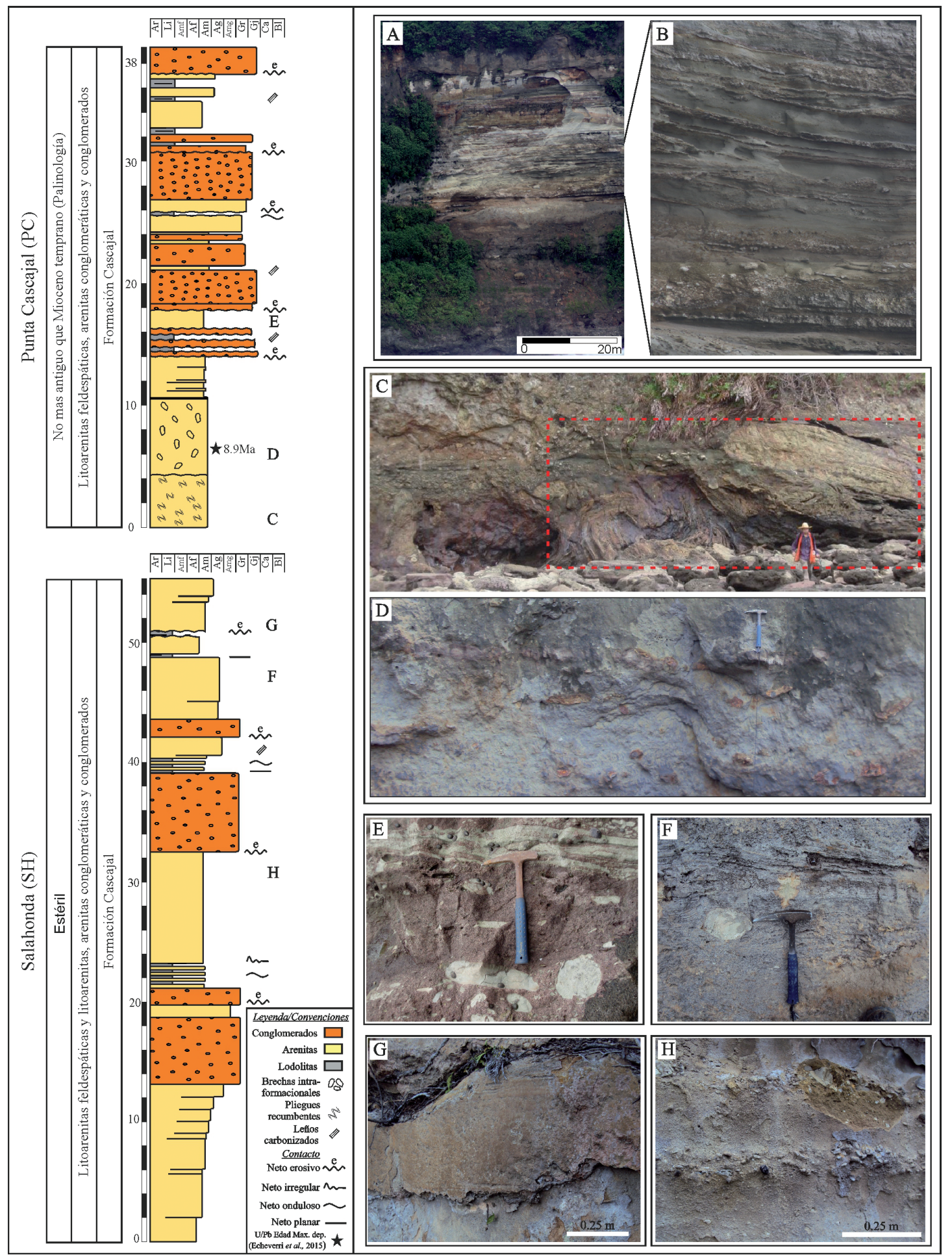

FIGURA 5. Columnas estratigráficas de la Formación Cascajal en los sectores de Punta Cascajal (PC) y Salahonda (SH). En las dos secciones se observa un amplio predominio de facies de arenitas y conglomerados sobre las facies de grano fino, además presentan un patrón de apilamiento grano-creciente. A y B. Vista panorámica de la sección PC; la aproximación muestra intercalaciones de arenitas y conglomerados con geometrías onduladas, lenticulares, canaliformes, o en cintas, con contactos netos erosivos. C. Estratos de litoarenitas feldespáticas de grano fino con pliegues recumbentes y segmentos dislocados (resaltados en rojo). D. Capas de litoarenitas feldespáticas de grano fino con textura brechada. E. Intraclastos de lodolita embebidos en arenitas macizas gruesas. F. Arenitas laminadas con intraclastos de lodolita. G. Capa gruesa de arenita de grano grueso, maciza, suprayaciendo en contacto neto erosivo a limolitas arenosas. H. Intercalación de arenitas gruesas, macizas, con cintas de conglomerados de guijos. 
En el sector de El Morro se presentan litoarenitas feldespáticas, volcánicas, de grano fino hasta grueso, macizas o con laminación difusa indiferenciada. En algunos segmentos estas litoarenitas son fosilíferas (nanofósiles, foraminíferos, bivalvos y gasterópodos), o están intensamente cementadas por carbonato y óxido de hierro. En otros segmentos se observan paleocanales con bases erosivas y onduladas, conformados por sets decimétricos de arenitas finas a medias con estratificación inclinada a gran escala (FIGURAS 6A y B). Es frecuente observar estructuras con geometrías canaliformes, con contactos erosivos hacia la base y ondulados hacia el tope (FIGURAS 6B y C); internamente presentan diversidad de facies interdigitadas de conglomerados de gránulos y guijos con presencia de bioclastos, arenitas conglomeráticas y arenitas con gradación normal y laminación plana paralela (FIGURAS 6C, D y E). Estas rocas son cortadas por una serie de diques de inyección clástica, con espesores centimétricos y texturas masivas, brechoides y laminadas (FIGURAS 6F, G y H). Las texturas brechoides, contienen fragmentos lutíticos incorporados durante el evento de inyección. Estos fragmentos contienen nanofósiles calcáreos del Mioceno superior, lo que permite asociarlos con las lodolitas de plataforma - prodelta de la formación San Agustín (Echeverri et al., 2012).

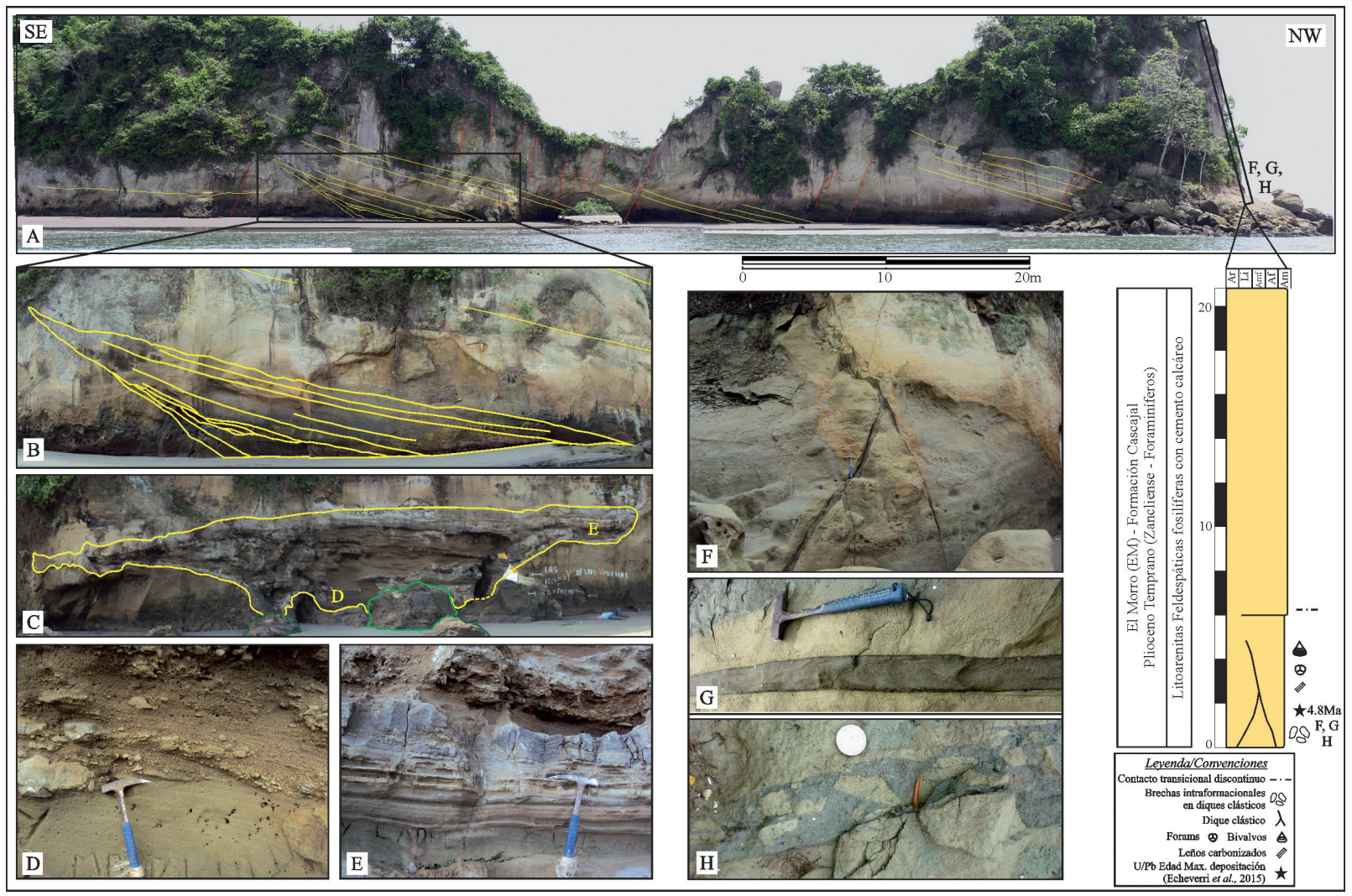

FIGURA 6. Columna estratigráfica de la Formación Cascajal en el sector de la isla de El Morro (EM). A. Vista panorámica que muestra el acantilado del sector de "el arco de la Isla del Morro", constituido por una sucesión monótona de litoarenitas feldespáticas. Se resalta la estratificación discontinua de arenitas con geometría canaliforme, y la localización de la columna estratigráfica. B. Estructura canaliforme de arenitas finas a muy finas con estratificación cruzada a gran escala. C. Paleocanal con geometría irregular y bases erosivas. D. Relleno de canal constituido por intercalación de arenitas medias, laminadas y arenitas muy gruesas, conglomeráticas con cintas y lentes conglomeráticos. E. Intercalación de capas delgadas y medias de arenitas con cemento calcáreo y laminación plana paralela, a su vez, suprayacidas por niveles conglomeráticos. F. Diques de inyección clástica arenosos con límites rectos, cortando a niveles potentes de arenitas finas a medias, homogéneas. G. Dique de inyección clástica con bandeamiento interno difuso. H. Dique de inyección clástica con textura brechoide.

En el sector de Curay, se presenta un límite paraconforme erosivo que define el contacto entre las lodolitas de la formación San Agustín y una capa de litoarenita media, conglomerática con intraclastos lodosos de la Formación Cascajal (FIGURA 7D). Esta sección, que representa el segmento basal de la Formación Cascajal en superficie, está constituida por una alternancia de facies heterolíticas, con capas lenticulares y ondulosas de arenitas conglomeráticas (FIGURA 7A), arenitas finas y muy finas, lodosas, con abundantes fragmentos 
de plantas carbonizadas, dispersos o concentrados en láminas (FIGURA 7B y C). Pueden presentar laminación plana paralela e inclinada, contactos erosivos con intraclastos lodosos (FIGURA 7D) y estructuras de deformación sin-sedimentaria.

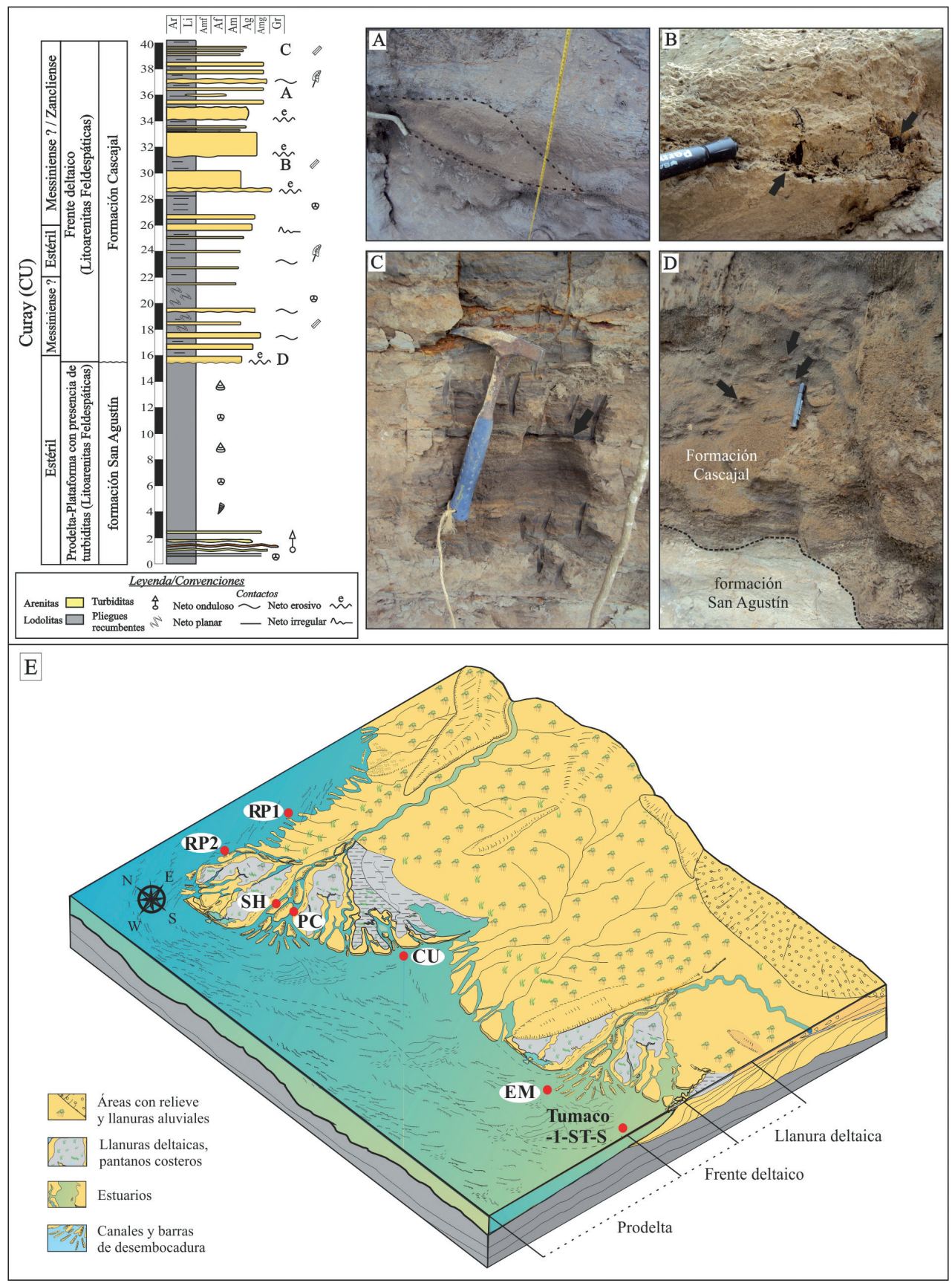

FIGURA 7. Columna estratigráfica de las formaciones San Agustín y Cascajal en el sector de Curay (CU). El contacto entre estas unidades es paraconforme erosivo, representado por la desaparición de intervalos muy gruesos de turbiditas y lodolitas fosilíferas, y aparición de capas medias y gruesas de arenitas y sucesiones heterolíticas con estructuras de deformación sin-sedimentaria. A. Lente de arenita media a fina embebido en facies heterolíticas con dominio de limolitas. Escala del lente $0,65 \times 0,15 \mathrm{~m}$. B. Se resaltan restos de plantas y fragmentos vegetales carbonizados en el tope de un estrato de arenita de grano fino a muy fino. C. Facies heterolíticas con láminas de lodolitas ricas en materia orgánica. D. Se resaltan intraclastos limosos en litoarenitas feldespáticas conglomeráticas, en contacto paraconforme erosivo con las facies lodosas de la formación San Agustín. E. Bloque diagrama generalizado para la Formación Cascajal, representando todas las secciones estudiadas en un ambiente de sedimentación deltaico (Pozo ANH-Tumaco 1-ST-S, EM: El Morro, CU: Curay, PC: Punta Cascajal, SH: Salahonda, RP1: Río Patía 1, RP2: Río Patía 2). 
En el sector del delta del Río Patía, se reporta el levantamiento de $\sim 50 \mathrm{~m}$ de columnas estratigráficas aisladas, constituidas por sucesiones granocrecientes de capas generalmente sub-horizontales, de espesor medio a muy grueso $(0,15$ a $4 \mathrm{~m})$, de litoarenitas feldespáticas, volcánicas, muy finas hasta medias, y ocasionalmente gruesas y muy gruesas (Patiño et al., 2011). Pueden ser macizas o presentar laminación plana paralela y ondulada, frecuentemente alternadas con capas medias hasta muy gruesas (de 0.2 a $3.4 \mathrm{~m}$ ) de limolitas y conglomerados macizos matriz-soportados. Las litoarenitas y conglomerados matriz-soportados pueden presentar fósiles de bivalvos y gasterópodos (FIGURAS 7A y B). Son frecuentes los intraclastos lodosos y material volcánico retrabajado.
Paleontología: el pozo ANH-Tumaco 1-STS presenta en los intervalos $135-257$ y $257-350 \mathrm{~m}$ fósiles bien preservados, principalmente bivalvos, gasterópodos, equinodermos, foraminíferos, restos de peces y de plantas (FIGURAS 8E y F). El intervalo 350$540 \mathrm{~m}$ presenta crustáceos, escafópodos, serpúlidos, equinodermos, fragmentos de corales(?), foraminíferos, bivalvos, gasterópodos y restos de peces y plantas (FIGURAS 8C Y D).

En afloramientos se presentan abundantes cutículas de dicotiledóneas (e.g. Curay, FIGURA 7B) y fragmentos de madera carbonizados, dispersos y a manera de láminas milimétricas (e.g. El Morro, Curay, Punta Cascajal), mientras que los foraminíferos, bivalvos y gasterópodos son más escasos y sólo aparecen en la sección de El Morro y en el sector del delta del río Patía (FIGURAS 8A y B).
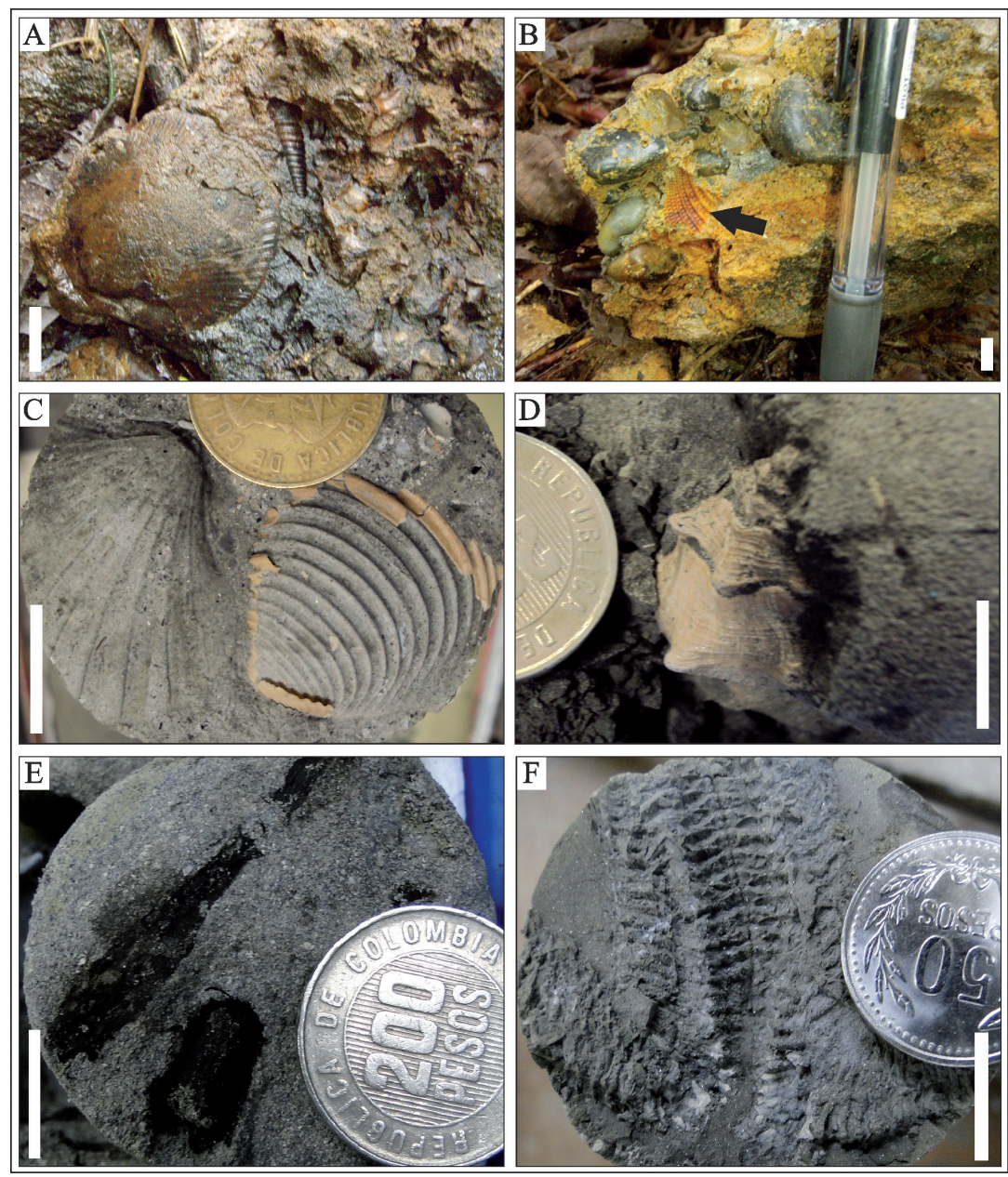

FIGURA 8. Contenido fosilífero de la Formación Cascajal en el sector del delta del río Patía (RP1 y RP2; Patiño et al. 2011 ). A. Litoarenitas fosilíferas de grano fino a medio, lodosas, con presencia de bivalvos y gasterópodos. B. Conglomerado polimíctico matriz soportado con líticos de chert, lodolitas, cuarzo lechoso y bivalvos (flecha negra). Contenido fosilífero de la Formación Cascajal en el pozo ANH-Tumaco 1-ST-S. C. Moldes externos de bivalvos presentes en limolitas arenosas. Metro 442,45. D. Molde externo de gasterópodo en limolita arenosa. Metro 385,55. E. Fragmentos de plantas carbonizados en arenita lodosa. Metro 221,05. F. Equinodermo en limolita arenosa. Metro 229,52. La escala corresponde a 1,2 cm. 
Micropaleontología: el pozo ANH-Tumaco 1-ST-S presenta un abundante y diverso contenido de polen y esporas (ANH-Universidad de Caldas 2011b). Algunos niveles presentan además palinomorfos marinos (quistes de dinoflagelados y foraminíferos). La presencia de: Clavainaperturites microclavatus, Echitricolporites mcneillyi, Cyatheacidites annulatus, Retipollenites crotonicollumelatus, Foveotriletes ornatus, Palaeosantalacaepites cingulatus, Malvacipolloides maristellae, Echiperiporites scabrannulatus, Nijssenosporites fossulatus, Retitriletes sommeri, Crototricolpites finitus, Corsinipollenties psilatus, Psilabrevitricolporites triangularis y Polypodiaceisporites pseudopsilatus. Esta asociación permite correlacionar el pozo con la Zona T-17 de Jaramillo et al. (2011) y con las Zonas VII-Asterácea y VIII- Fenestrites longispinosus de Lorente (1986), precisando que la edad no es más antigua que Messiniense (Mioceno tardío) - Zancliense (Plioceno temprano) (ANH-Universidad de Caldas, 2011b). Adicionalmente, análisis de foraminíferos reportan los siguientes marcadores: Neogloboquadrina acostaensis, $N$. atlantica, $N$. pachyderma, Orbulina universa, Globigerinella calida s.l., Globigerina praebulloides, G. falconensis, Globigerinoides obliquus, G. extremus, G. ruber, Globigerinita uvula, Menardella menardii "Globorotalia" cultrata, Zeaglobigerina nepenthes, Sphaeroidinellopsis seminulina, Dentoglobigerina altispira, Globoquadrina dehiscens y G. praedehiscens, los cuales sugieren edades desde el Messiniense (Mioceno tardío) hasta el Zancliense (Plioceno temprano) (ANH-Universidad de Caldas, 2011b).

Aunque los nanofósiles calcáreos en el pozo ANHTumaco 1-ST-S son escasos, se han identificado Sphenolithus abies, Helicosphaera carteri $y$ reticulofenéstridos, que se asocian a las biozonas NN15/ CN11b, NN11/CN9 (Martini, 1971; Okada and Bukry, 1980), indicando edades aproximadas desde Tortoniense (Mioceno tardío) al Zancliense (Plioceno temprano) (ANH-Universidad de Caldas, 2011b).

En afloramientos, la sección de Curay presenta buen recobro de polen y esporas, con ocurrencias de Cyatheacidites annulatus, Clavainaperturites microclavatus, Fenestrites spinosus, Echitricolporites spinosus, Nijssenosporites fossulatus, Polypodiaceoisporites pseudopsilatus, Psilatriletes lobatus y Zonocostites ramonae. La asociación palinológica encontrada se correlaciona con la Zona T-17 y Zona T-18 de Jaramillo et al. (2011) y con la Zona VII-Asteraceae (?) de Lorente (1986), indicando una edad no más antigua que el Messiniense-Zancliense
(Mioceno tardío-Plioceno). Esta edad es parcialmente confirmada por el escaso contenido nanoplantónico presente en las secciones de El Morro y Curay, con presencia de Sphenolithus abies, Reticulofenestra pseudoumbilicus y Discoaster quinqueramus (biozonas NN11b/CN9b; Martini, 1971; Okada and Bukry, 1980), que corresponden a biohorizontes de referencia de edad Messiniense. Estos datos se complementan con análisis de foraminíferos que reportan los siguientes marcadores de Neogloboquadrina acostaensis, N. pachyderma, Globigerinoides obliquus, G. mitra, G. bulloideus, Globorotalia cultrata, Tenuitellinata angustiumbilicata, Globoturborotalita rubescens, Menardella menardii, Sphaeroidinellopsis seminulina, Uvigerinella califórnica ornata, Uvigerina flintii, U. juncea y Angulogerina/Trifarina angulosa, indicando una edad Messiniense - Zancliense tardío (ANH-Universidad de Caldas, 2011a).

Icnofósiles: en el pozo ANH-Tumaco 1-ST-S, tanto las facies lodosas como arenosas presentan moderada a alta abundancia y diversidad de icnofósiles bien preservados (FIGURAS 4F, G, H y I); mientras que en afloramientos son difíciles de observar debido a la intensa meteorización. Se identificó una asociación dominada por la presencia de Asterosoma, (?) Bichordites, Diplocraterion, Ophiomorpha, Planolites, Phycosiphon, Rhizocorallium, (?) Rosselia, Siphonichnus, Terebellina, Thalassinoides. En varios sectores de dominio volcánico se destaca la ocurrencia como traza monoespecífica del icnogénero Phycosiphon (FIGURA 4F). Los icnogéneros reconocidos en su mayoría, presentan estructuras combinadas de alimentación y habitación (Fodinichnia) más o menos temporales, simples y complejas, construidas por organismos depositívoros. Estas estructuras presentan relleno activo producto del procesamiento del alimento. La orientación de las trazas es variable pero se observa un predominio de trazas verticales sobre las horizontales (FIGURA 4I). La asociación de trazas fósiles observada es indicativa de la icnofacies Cruziana (Seilacher, 1964; MacEachern et al., 2007; MacEachern and Bann, 2008), basados en: 1) variedad de categorías etológicas, 2) abundancia de trazas de alimentación-depositación y en menor proporción alimentación-suspensión, 3) alta presencia de trazas producidas por fauna móvil y esporádica presencia de burrows permanentes, y 4) alta icnodiversidad y abundancia de trazas. MacEachern et al. (2007), ha propuesto subdivisiones de la icnofacies Cruziana a partir de las transiciones con las icnofacies que anteceden y proceden a esta. Así, la suite de trazas fósiles encontradas se relaciona directamente con la expresión "proximal" de la icnofacies Cruziana la 
cual se desarrolla en un ambiente de frente de playa inferior, frente deltaico a prodelta. El dominio de trazas con comportamiento alimentación-depositación y el significativo registro de trazas de vivienda asociados con organismos de alimentación-suspensión, sugiere un estado persistente por encima del nivel de acción de olas, que permite la suspensión del alimento sobre la interfaz agua/sedimento. Por otro lado, los episodios volcánicos y/o tormentas imparten un control considerable en el carácter del frente de playa inferior, destruyendo y enterrando las comunidades bentónicas (Pemberton et al., 1992). Durante el registro pos-vulcanismo o pos-tormenta, la colonización inicial de los depósitos volcánicos y/o tempestitas generalmente corresponde a estructuras oportunistas monoespecíficas de vivienda/ suspensión-alimentación, como Phycosiphon $(P h)$ (FIGURA 4F), las cuales típicamente no reflejan la comunidad residente original. Cuando las condiciones de buen tiempo retornan puede volver a ocurrir la colonización de la suite de trazas fósiles original (Wetzel, 2008; Pemberton et al., 2012).

Correlaciones: localmente la parte superior de la sección de Curay (15,4-40 m) se correlaciona con el intervalo inferior $(135-257 \mathrm{~m})$ del pozo ANHTumaco 1-ST-S, mientras que las secciones de Punta Cascajal, Salahonda, el área deltaica del río Patía, y El Morro, podría correlacionarse aproximadamente con el segmento medio $(257-350 \mathrm{~m})$ definido en el Holoestratotipo (FIGURAS 3 y 8). Regionalmente la Formación Cascajal se correlaciona con los conglomerados de la Formación Guapi observados en el tope de los pozos Tambora-1 y Sandi-1, y en la llanura costera del departamento de Cauca (Van der Hammen, 1958; Suárez-Rodríguez, 1990) hacia el sur de la cuenca Tumaco; con los conglomerados y areniscas de la Formación Raposo (Aspden y Nivia, 1984) en la llanura del Pacífico del Valle del Cauca; y con las areniscas con intercalaciones de conglomerados e intervalos ricos en lignito del miembro Súa (Evans and Whittaker, 1982; Deniaud 1998; Di Celma et al., 2010), en la cuenca Borbón en el NW del Pacífico ecuatoriano (FIGURAS 1 y 2).

Génesis: el segmento basal del pozo ANH-Tumaco 1-ST-S $(135$ - $257 \mathrm{~m})$ presenta un predominio de arenitas finas a medias y lodolitas, bioturbadas, con escasas intercalaciones de conglomerados de gránulos y guijos. Esta distribución de facies, junto con la presencia de lentes carbonosos con fragmentos leñosos, fósiles de origen marino y glauconita, se interpreta como un ambiente sedimentario de frente deltaico distal. El segmento medio $(257-350 \mathrm{~m})$, está dominado por potentes intervalos de facies arenosas - conglomeráticas como relleno de canales, con estructuras internas macizas y laminadas, y bases erosivas e intraclastos lodosos arenáceos que sugieren sedimentación de alta energía en ambientes de frente deltaico proximal (subambientes de canales distributarios y barras de desembocadura). Este conjunto de facies gruesas, y la presencia de lentes carbonosos y fragmentos de plantas (leños y cutículas) indican mayor interacción y proximidad de fuentes continentales con respecto al intervalo infrayacente, sin embargo, la bioturbación, la presencia de foraminíferos y moluscos marinos descartan un ambiente sedimentario de áreas emergidas (e.g. llanura deltaica, fluvial). Hacia el tope $(350-540 \mathrm{~m})$, el dominio de lodolitas fosilíferas $\mathrm{y}$ arenitas de grano fino marcan la profundización del ambiente de depósito con relación al segmento medio. Los contactos erosivos e intraclastos lodosos presentes en arenitas, sugieren el eventual retrabajamiento de la superficie de depósito. La presencia de glauconita, pellets glauconitizados, bioturbación y diversidad de fósiles marinos es mayor con respecto a los intervalos infrayacentes, sugiriendo ambientes más distales a la línea de costa con condiciones propicias para la colonización de organismos (FIGURA 7E). Para este intervalo se propone un ambiente sedimentario de frente deltaico distal - prodelta.

Por otro lado, en afloramientos son comunes las sucesiones granocrecientes de arenitas y conglomerados, en estratos amalgamados, macizos o laminados, con geometrías lenticulares, onduladas y canaliformes, y contactos basales definidos por superficies erosivas. Estas características, junto con la presencia de intraclastos lodosos, evidencian la erosión y removilización de la superficie de depósito por flujos de corrientes y/o hiperconcentrados (Salahonda, Cascajal y Curay). Es común observar estructuras sedimentarias indicadoras de corrientes, tales como estratificación plana paralela, inclinada planar y tangencial, sugiriendo variaciones en el régimen de flujo durante la sedimentación; sin embargo también se presentan estructuras internas macizas de espesores centimétricos hasta decamétricos, interpretadas como producto del emplazamiento de flujos hiperconcentrados de origen volcánico a la línea de costa o por intensa bioturbación. La abundancia de láminas carbonosas y fragmentos de plantas está presente en todas las secciones estudiadas, mientras que el pobre registro de bivalvos, gasterópodos, nanofósiles calcáreos y foraminíferos solo está presente en las secciones de El Morro, Río Patia y Curay. Se propone un ambiente de sedimentación de canales distributarios y barras de desembocadura en un frente deltaico proximal (El Morro, Río Patia y Curay) y frente deltaico - fluvial 
para las secciones de Salahonda y Cascajal (FIGURA $7 \mathrm{E})$.

La presencia de estructuras de deformación sinsedimentaria (pliegues recumbentes, brechas, diques clásticos) sugieren inestabilidad del relleno sedimentario, cuyos mecanismos de disparo pueden estar asociados con actividad sísmica, diapirismo de shale, sobrecarga de sedimentos, o a altas pendientes en la superficie de depósito.

El incremento en las facies arenosas y conglomeráticas de frente deltaico - prodelta de la Formación Cascajal, que suprayacen en contacto paraconforme erosivo a los dominios lodosos de plataforma - prodelta de la formación San Agustín, se genera como respuesta a eventos regionales que afectaron la margen pacífica colombo - ecuatoriana durante el Neógeno, tales como, descensos del nivel eustático en el límite Mioceno Plioceno (Haq et al., 1987), incremento de abanicos volcaniclásticos provenientes del arco magmático (Murcia et al., 2011), y a la exhumación registrada entre 6 y 3,5 Ma de la zona de ante-arco e intra-arco, y las cordilleras Occidental de Colombia y Real de Ecuador (Barbosa, 2012; Spikings and Crowhurst, 2004). La aproximación de elementos de mayor flotabilidad en la placa Nazca a la trinchera, o el desplazamiento oblicuo del ante-arco, podrían ser los causantes de estas modificaciones, causando igualmente la deformación y exhumación de las secuencias sedimentarias del Mioceno en la cuenca Tumaco onshore y del alto estructural Remolinogrande - Gorgona (Marcaillou and Collot, 2008; López, 2009; Martínez and López, 2010; Echeverri et al., 2015).

\section{SÍNTESIS Y CONCLUSIONES}

La revisión y evaluación de las características litoestratigráficas que definen el miembro Cascajal (sensu Nivia et al., 2003) no son concordantes con las observaciones del pozo ANH-Tumaco 1-ST-S, ni con los afloramientos visitados en la bahía de Tumaco. La secuencia estudiada es dominantemente siliciclástica y contrasta con el concepto calcáreo original del miembro Cascajal. Por esta razón, a partir de la integración de los nuevos datos obtenidos con la información estratigráfica disponible se redefine el concepto anterior, ya que el contenido de carbonatos presente en las rocas analizadas es producto de la fuerte cementación calcárea observada en algunos estratos, y a niveles con altos porcentajes de bioclastos en lodolitas, limolitas y arenitas fosilíferas con un contenido superior al $50 \%$ de fósiles. Sin embargo, la adquisición de nuevos datos estratigráficos y análisis petrográficos sistemáticos podrían caracterizar e identificar posibles interestratificaciones calcáreas.

A partir de la integración de datos micropaleontológicos, quimio-estratigráficos ${ }^{87} \mathrm{Sr} /{ }^{86} \mathrm{Sr}$ (Rosero et al., 2012), y geocronológicos (Echeverri et al., 2015), la edad de la Formación Cascajal se extiende desde la parte superior del Mioceno superior hasta el Plioceno inferior (Messiniense parte superior a Zancliense). Estos datos, correlacionados con las edades de nanofósiles calcáreos de la infrayacente formación San Agustín, al N de Curay (Bedoya et al., 2013), constriñen la edad de esta unidad entre el Messiniense parte superior y el Zancliense (de $6,85$ a $3,6 \mathrm{Ma})$.

Se propone emplear el término Formación Cascajal al conjunto de arenitas y conglomerados, y en menor proporción limolitas, lodolitas y facies heterolíticas de grano fino, presentes hacia el segmento sur de la cuenca Tumaco. Las secciones de referencia empleadas en la definición formal de la Formación Cascajal se localizan en los pozos ANH-Tumaco 1-S-T-S, ANH-Tumaco 1-S-T-P, Remolinogrande-1, y en los afloramientos presentes en inmediaciones de la bahía de Tumaco y del sistema deltaico del río Patía. La presencia de moluscos (bivalvos, gasterópodos, escafópodos), equinodermos, serpúlidos, crustáceos, foraminíferos (principalmente bentónicos), e icnofósiles, es común tanto en facies arenosas como lodosas. La distribución de facies, fósiles e icnofósiles de afinidad marina, permiten plantear un ambiente de sedimentación de frente deltaico - prodelta, oxigenado, con luminosidad y disponibilidad de nutrientes que favoreció la colonización de organismos. Adicionalmente, la abundancia de restos de plantas carbonizadas, polen y esporas, indican ambientes con gran influencia y proximidad de fuentes continentales.

La fertilidad de clastos de pumitas, tobas y lavas andesíticas - dacíticas en todas las facies estudiadas representa una marcada influencia de vulcanismo principalmente explosivo en la sedimentación, ya sea como productos primarios o como rocas epiclásticas generadas por remoción de material volcánico proveniente del arco. Este registro se correlaciona con el emplazamiento de abanicos volcaniclásticos hacia la llanura costera del Pacífico (Murcia et al., 2011), con los primeros episodios de construcción del Neógeno volcánico en el altiplano nariñense (Pinilla-Ocampo et al., 2008) y con los pulsos magmáticos del Mioceno tardío -Plioceno reportados en el suroccidente de Colombia (Echeverri et al., 2015). 


\section{AGRADECIMIENTOS}

Esta investigación está enmarcada en los contratos 092 y 093 desarrollados por la Agencia Nacional de Hidrocarburos-ANH y el Instituto de Investigaciones en Estratigrafía-IIES de la Universidad de Caldas. Agradecemos a la ANH por permitir emplear datos de su propiedad. A M. Moreno por las discusiones estratigráficas. G. Hincapié, E.C Ruiz, J. García, R. Hernández y demás colaboradores del IIES por su apoyo durante la fase de campo y en la elaboración de algunas figuras. Agradecemos las sugerencias y comentarios de dos revisores anónimos que enriquecieron la estructura del artículo.

\section{REFERENCIAS}

ANH - Universidad de Caldas. 2011a. Estudio geológico integrado en la Cuenca Tumaco Onshore. Síntesis cartográfica, sísmica y análisis bioestratigráfico, petrográfico, geocronológico, termocronológico y geoquímico de testigos de perforación y muestras de superficie. Contrato No. 092 de 2009: Cartografía geológica a escala 1:100.000, cuenca Tumaco onshore. Manizales, Colombia, 215p.

ANH - Universidad de Caldas. 2011b. Estudio integrado de los núcleos y registros obtenidos de los pozos someros (slim holes) perforados por la ANH, Contrato No. 093 de 2009.Manizales, Colombia, 215p.

Arango, J.L., y Ponce, A. 1980. Mapa geológico generalizado del departamento de Nariño escala 1:400.000. Reimpresión 1996. República de Colombia. Ministerio de Minas y Energía. Instituto de Investigaciones Geológico-Mineras. Bogotá, Colombia, $47 \mathrm{p}$.

Aspden, J.A. 1984. The geology of the Western Cordillera and Pacific coastal plain in the departament of Valle del Cauca (Sheets 261, 278, 279, 280 and 299). Report No. 7. INGEOMINAS - Misión Británica. Cali, Colombia, 57p.

Aspden, J.A., y Nivia, A. 1984. La geología de la plancha 278-Bahía de Buenaventura: escala 1:100.000, INGEOMINAS - Misión Británica (B.G.S). Cali, Colombia.

Barbosa, A.A. 2012. Historias térmicas de la cuenca Tumaco y sector sur de la Cordillera Occidental: Implicaciones para la generación de hidrocarburos y evolución tectónica del noroccidente de Suramérica. Universidad de Caldas. Manizales, Colombia, 95p.
Becerra, I., y Usma, V. 2008. Modelamiento geológicogeofísico a la altura de $3 \mathrm{~N}$ desde el graben de Yaquina hasta el Cratón de la Guyana. Facultad de Ciencias Exactas y Naturales, Universidad de Caldas. Manizales, Colombia, 58p.

Bedoya, E.L., Flores, J.A., y Pardo, A. 2013. Nanofósiles calcáreos y bioestratigrafía del Mioceno Tardío del SW de la cuenca Tumaco onshore (Pacífico colombiano). Boletín de Geología, 35: 55-66.

Cediel, F., Restrepo, I., Marín-Cerón, M.I., DuqueCaro, H., Cuartas, C., Mora, C., Montenegro, G., García, E., Tovar, D., and Muñoz, G. 2010. Geology and Hydrocarbon Potential, Atrato and San Juan Basins, Chocó (Panamá) Arc, Colombia, Tumaco Basin (Pacific Realm).ANH. Medellín, 172p.

Cohen, K.M., Finney, S.C., Gibbard, P.L., and Fan, J.X. 2013. The ICS International Chronostratigraphic Chart. Episodes, 36: 199-204.

Correa, I., Hermelin, M., Martínez, J.I., Sierra, G., Toro, G.E., y Restrepo, J.D. 2008. Cuenca Tumaco (onshore y offshore), Cuenca San Juan y Cuenca Atrato. Inventario, interpretación y evaluación de la información geológica disponible, elaboración de los paquetes técnicos y promocionales ronda de áreas abiertas 2009. Convenio Universidad EAFIT-ANH. Medellín, Colombia, 113p.

Deniaud, Y. 1998. Evolución tectono-sedimentaria de las cuencas costeras Neógenas del Ecuador. Convenio Petroproduccion / ORSTOM. Quito, Ecuador, 74p.

Di Celma, C., Cantalamessa, G., Landini, W., and Ragaini, L. 2010. Stratigraphic evolution from shoreface to shelf-indenting channel depositional systems during transgression: Insights from the lower Pliocene Súa Member of the basal Upper Onzole Formation, Borbón Basin, northwest Ecuador. Sedimentary Geology, 223(1-2): 162-179.

Earth Satellite Corporation. 1999. Geology of the Pacific Coast of Colombia. Rockville, Maryland, 36p.

Echeverri, S., Cardona, A., Pardo A., Monsalve, G., Borrero, C., Valencia, V., Rosero S., and López, S. 2015. Regional provenance from southwestern Colombia fore-arc and intra-arc basins: implications for Middle to Late Miocene orogeny in the Northern Andes. Terra Nova, 27 (5): 356-363.

Echeverri, S., Pardo, A., Hincapié, G., Cardona, A., Rosero, S., and López, S. 2012. Dating clastic injection 
events in Tumaco basin: integration of geochronology and stratigraphic proxies. VIII South American symposium on Isotope Geology - SSAGI. Medellín, Colombia, 93p.

Echeverri, S., Borrero, C., Moreno, M., Pardo, A., y Castillo, H. 2011. Nomenclatura estratigráfica para la sucesión neógena expuesta en la bahía de Tumaco (cuenca Tumaco costa adentro, SW de Colombia) - Redefinición y formalización. XIV Congreso Latinoamericano de Geología y XIII Congreso Colombiano de Geología. Medellín, Colombia.

Escovar, R., Gómez, L.A., y Ramírez, J.R. 1992. Interpretación de la Sísmica Tumaco 90 y evaluación preliminar del área: Bogotá. Empresa Colombiana de Petróleos (ECOPETROL). Bogotá, Colombia, 74p.

Evans, C.D.R., and Whittaker, J.E. 1982. The geology of the western part of the Borbón Basin, North-west Ecuador. Geological Society, 10 (1):191 - 198.

Galindo, V., y Torres, M.E. 1995. Mapa Geológico Compilado de la Cuenca de Tumaco. Ecopetrol Geología Sistematizada Ltda.

González, H. 2008. Investigación Integral del Anden Pacífico Colombiano. Convenio administrativo INGEOMINAS-IGAC. Tomo 1. Bogotá, Colombia, pp. 83-86.

Haq, B.U., Hardenbol, J., and Vail, P.R. 1987. Chronology of fluctuating sea levels since the Triassic (250 million years ago to present). Science, 235: 11561167.

INGEOMINAS-IGAC. 2005. Mapa geológico a escala 1:100.000 de las planchas: 361 BIS Tomo, 383 Tumaco, $384 \mathrm{La}$ Chorrera, 407 Cabo Manglares y 408 Barbacoas.

ISSC. 1994. International Subcommission on Stratigraphic Classification of IUGS, International Commission on Stratigraphy, International Stratigraphic Guide (2a edition, Amos Salvador, ed.). International Union of Geological Sciences y Boulder, Colorado, Geological Society of America. Trondheim, Noruega, $214 p$.

Jaramillo, C.A., Rueda, M., and Torres, V. 2011. A palynological zonation for the Cenozoic of the Llanos and Llanos Foothills of Colombia. Palynology, 35 (1): 46-84.
López, E. 2009. Evolution tectono-stratigraphique du double bassin avant - arc de la marge convergente Sud Colombienne - Nord Equatorienne pendant le Cénozoïque. GeoAzur. Nice, France, 349p.

Lorente, M.A. 1986. Palynology and Palynofacies of the Upper Tertiary in Venezuela. Dissertationes botanicæ. Berlin, 222p.

MacEachern, J.A., Bann, K.L., Pemberton, S.G., and Gingras, M.K. 2007. The Ichnofacies paradigm: Highresolution paleoenvironmental interpretation of the rock record. In: MacEachern, J.A., Bann, K.L., Gingras, M.K., and Pemberton, S.G. (Eds.). Applied Ichnology. Society for Sedimentary Geology Short Course Notes, 52: 27-64.

MacEachern, J.A., and Bann, K.L. 2008. The role of ichnology in refining shallow marine facies models. In: Hampson, G., Steel, R., Burgess, P., Dalrymple, (Eds.). Recent Advances in Models of Siliciclastic ShallowMarine Stratigraphy. SEPM Special Publication, 90: 73-116.

Marcaillou, B., and Collot, J.Y. 2008. Chronostratigraphy and tectonic deformation of the north Ecuadorian-south Colombian offshore Manglares forearc basin. Marine Geology, 255: 30 - 44.

Martínez, J.O., and López, E. 2010. High-resolution seismic stratigraphy of the late Neogene of the central sectorof the Colombian Pacific continental shelf: A seismic expression of an activecontinental margin. Journal of South American Earth Sciences, 31: 28-44.

Martini, E. 1971. Standard Tertiary and Quaternary calcareous nannoplankton zonation. In: Farinacci, A. (Ed.). Proceedings of the II Planktonic Conference (1970). Roma, 2: 739-785.

Montoya, D. 2002. Mapa geológico a escala 1:100.000 de las planchas: 240 Pichimá, 259 Malaguita y 260 Aguas Claras.

Murcia, H.F., Borrero, C., Pardo, A., y Castillo, H. 2011. Depósitos volcaniclásticos en la cuenca de antearco de Tumaco: Evidencia de actividad volcánica en la Cordillera Occidental de Colombia. XIV Congreso Latinoamericano de Geología, Medellín, Colombia, pp. 245-246.

NASC. 2005. North American Stratigraphic Code. North American Commission on stratigraphy nomenclature. AAPG Bulletin, 89 (11): 1547-1591. 
Nivia,A., Pérez, C., y Sepúlveda, J. 2003. Geomorfología y Geología de la Plancha 383 Tumaco. INGEOMINAS. Cali, Colombia, 37p.

Okada, H., and Bukry, D. 1980. Supplementary modification and introduction of code numbers to the low-latitude coccolith biostratigraphic zonation (Bukry, 1973; 1975). Marine Micropaleontology. 5: 321-325.

Oppenheim, V. 1949. Geología de la costa sur del pacífico de Colombia. Instituto Geofísico de los Andes Colombianos, 1: 1 -23.

Patiño, J.C., Camargo, G., Caicedo, J.C., Gómez, H., Ariza, S., Suárez, F., Valencia, L.Y., Contreras, K., y Niz, L.D. 2008. Geología de superficie y geoquímica de rocas y crudos de la subcuenca del San Juan (Chocó). Informe final Servigecol Ltda. Bogotá, Colombia, 131p.

Patiño, J.C., Gómez, H., Grajales, J.A., Dallos, C.C., Yepes, A.M., y Navarrete, L.A. 2011. Levantamiento de una sección geológica a escala 1.100 .000 en el afluente principal del río Patía. Contrato Universidad de Caldas - Servigecol Ltda. Número 063 de 2010.

Pemberton, S.G., MacEachern, J.A., and Ranger, M.J. 1992. Ichnology and event stratigraphy: the use of trace fossils in recognizing tempestites. In: Pemberton, S.G. (Ed.), Application of Ichnology to Petroleum Exploration. A Core Workshop. SEPM Core Workshop Notes, 17: 85-117.

Pemberton, S.G., MacEachern, J.A., Dashtgard, S.E., Bann, K.L., Gingras, M.K., and Zonneveld, J.-P. 2012. Shorefaces. In: Knaust, D., Bromley, R.G. (Eds.). Trace fossils as indicators of sedimentary environments. Elsevier, Amsterdam, 64: 563-604.

Pinilla-Ocampo, A., Ríos-Blandón, P.A., RodríguezRamos, B.P., Sánchez-Aguilar, J.J., Pulgarín-Alzate, B., Borrero-Peña, C.A., y Roa-Vargas, H.J. 2008. El Neógeno volcánico en el Altiplano Nariñense, suroccidente colombiano. Geología Colombiana, 33: 69-78.

Rosero, S., Silva, J.C., Ducea, M., Pardo, A., Echeverri, S., and López, S. 2012. Strontium isotope chronostratigraphy from Neogene successions in the Tumaco basin, SW Colombia. VIII South American symposium on Isotope Geology - SSAGI. Medellín, Colombia, $157 \mathrm{p}$.

Salazar, G. 2002. Mapa geológico a escala 1:100.000 de las planchas: 202 Pilizá y 221 Pizarro. INGEOMINAS.
Schlumberger. 2011. Pozo ANH-Tumaco 1-ST-P, evaluación de registros, Int. $750-4930 \mathrm{ft}$, escala 1:200. Cuenca Tumaco, Nariño - Colombia.

Seilacher, A. 1964. Biogenic sedimentary structures. In: Approaches to Paleoecology (Imbrie, J., and Newell, N. ed.), Chichester, UK, John Wiley y Sons, pp. 296-316.

Spikings, R.A., and Crowhurst, P.V. 2004. (U-Th) / The thermochronometric constraints on the late MiocenePliocene tectonic development of northern Cordillera Real and the Interandean Depression, Ecuador. Journal of South American Earth Sciences, 17: 239-251.

Suárez-Rodríguez, M. 1990. Estudio geológico regional e interpretación sísmica estratigráfica en la provincia sedimentaria de la costa pacífica. Empresa colombiana de petróleos GEX-ICP, 117p.

Suárez-Rodríguez, M. 2007. Geological framework of the Pacific coast sedimentary basins. Geología Colombiana, 32: 47-62.

T.G.T. Gamas. 2011. Registro gráfico compuesto pozo ANH-Tumaco 1-ST-P, Int. 40-11.738 ft, escala 1:500 Cuenca Tumaco, Nariño - Colombia.

Van der Hammen. 1958. Estratigrafía del Terciario y Maastrichtiano continental y tectogénesis de los Andes Colombianos. Investigaciones de Estratigrafía y Palinología, INGEOMINAS. Informe interno 1279. Boletín de Geología, 6(1-3): 53-54.

Wetzel A. 2008. Recent bioturbation in the deep South China Sea: a uniformitarian ichnologic approach. Palaios, 23: 601-615.

Trabajo recibido: junio 10 de 2015

Trabajo aceptado: septiembre 23 de 2016

Manuscrito publicado en internet: septiembre 29 de 2016 